\title{
Assessment of Foods Associated with Sodium and Potassium Intake in Japanese Youths Using the Brief-Type Self-Administered Diet History Questionnaire
}

\author{
Masayuki Okuda ${ }^{1, *(D)}$ and Satoshi Sasaki ${ }^{2}$ \\ 1 Graduate School of Sciences and Technology for Innovation, Yamaguchi University, \\ 1-1-1 Minami-Kogushi, Ube 755-8505, Japan \\ 2 Department of Social and Preventive Epidemiology, School of Public Health, The University of Tokyo, \\ 7-3-1 Hongo, Bunkyo-ku, Tokyo 113-0033, Japan; stssasak@m.u-tokyo.ac.jp \\ * Correspondence: okuda@yamaguchi-u.ac.jp; Tel.: +81-836-22-2231
}

Citation: Okuda, M.; Sasaki, S. Assessment of Foods Associated with Sodium and Potassium Intake in Japanese Youths Using the Brief-Type Self-Administered Diet History Questionnaire. Nutrients 2021, 13, 2345. https://doi.org/10.3390/ nu13072345

Academic Editor: Emily Sonestedt

Received: 21 June 2021

Accepted: 7 July 2021

Published: 9 July 2021

Publisher's Note: MDPI stays neutra with regard to jurisdictional claims in published maps and institutional affiliations.

Copyright: (c) 2021 by the authors. Licensee MDPI, Basel, Switzerland. This article is an open access article distributed under the terms and conditions of the Creative Commons Attribution (CC BY) license (https:/ / creativecommons.org/licenses/by/ $4.0 /)$.

\begin{abstract}
The identification of sodium and potassium intake in youths is an important step to preventing the increase of blood pressure in childhood. We examined food intake and estimated mineral intake using a brief-type self-administered diet history questionnaire (BDHQ) to test its validity as a comparison with urinary excretion in Japanese youths. The subjects were 5 th and 8 th graders ( $n=2377$ ), who completed the BDHQ and permitted the use of their overnight urine specimens. Sodium intake was poorly associated with sodium excretion $(R h o=0.048)$, and the coefficients of dietary potassium and a sodium-to-potassium molar ratio were $0.091-0.130$. Higher soybean paste (miso) intake and pickles were significantly associated with higher sodium excretion $(p \leq 0.005)$. However, these foods were positively associated with potassium excretion $(p=0.002-0.012)$, and not associated with an excreted sodium-to-potassium ratio. Fruits and dairy products were positively associated ( $p \leq 0.048$ ), whereas beverages were negatively associated with potassium excretion $(p \leq 0.004)$. The association of the sodium-to-potassium ratio was opposite to that of potassium $(p \leq 0.001)$. The choice of foods, potassium, and the sodium-to-potassium ratio assessed using the BDHQ are available as part of health education for youths, but the assessment of sodium intake in population levels should be carefully conducted.
\end{abstract}

Keywords: adolescents; brief-type self-administered diet history questionnaire; children; foods; potassium; sodium; sodium-to-potassium ratio; urinary excretion

\section{Introduction}

High sodium intake is one of the major health risks in people worldwide. It contributes largely to mortality, especially in East Asia and West-Pacific areas, through cardiovascular diseases, cancers, and kidney diseases [1]. Even in children, high sodium intake is related to high blood pressure [2-5], and further meta-analyses showed tracking of higher blood pressure from childhood to adulthood [6,7]. The reduction of sodium intake is important to control blood pressure (a public health challenge) in children [8]. High potassium intake and a low dietary sodium-to-potassium ratio should be also considered, with measures against high sodium intake, to prevent the increase of blood pressure in childhood $[9,10]$. Despite scarce literature about the associations between high potassium intake or a low dietary sodium-to-potassium ratio and blood pressure in youths [11,12], these nutritional indices have beneficial possibilities on blood pressure [13].

The identification of mineral intake is the first step for policy planning [14]. Processed foods are the main sources of dietary sodium in the UK and US [15], where food reformulation, such as bakery products, processed meats, dairy products, sauces, and convenience meals, may be targeted [14,16]. Conversely, discretionary use during cooking or eating is the main contributor to sodium intake in East Asian countries, such as from soy sauce in 
Japan and salt in China $[15,17]$. Public health education or consumer awareness campaigns may be efficient for implementing sodium reduction interventions in these countries [14]. Most data about food sources that policymaking is based on is derived from adult surveys, but foods contributing to sodium intake vary among different age groups [17-19].

Understanding individual and people's sodium intake is helpful for public health policy communication, raising motivation for habit change, and maintaining a healthy dietary habit. A brief and simple questionnaire may be useful for community settings. Uechi et al. reported that simple questions about consumption of soybean paste (miso) soup, salty foods, or noodle soup, and seasonings/condiments use were related to excess sodium intake measured using $24 \mathrm{~h}$ urinary sodium excretion in Japanese adults [20]. The score of the Salt Check Sheet consisting of 13 questions was correlated with 24-h urinary sodium excretion in adults [21]. The brief-type self-administered diet history questionnaire (BDHQ) with 64 food items, which takes 15-20 min to accomplish, is applicable for a large population survey [22]. Estimates from this questionnaire were associated with not only urinary sodium but also potassium excretion in adults [20,23]. The BDHQ for youths, with 55-64 food items modified from the adult version, may be useful to estimate sodium and potassium intake and foods related to high sodium and low potassium intake of children and adolescents. However, correlations between estimates from the BDHQ for youths and biomarkers other than sodium and potassium intake (nitrogen, carotenoids, tocopherols, and marine $\omega-3$ polyunsaturated fatty acids) were slightly lower than those in adults $[24,25]$. This study investigated whether estimates of sodium, potassium, and foods from the BDHQ for youths were associated with urinary excretion to test its validity and explored food intake related to sodium and potassium intake. The results are expected to provide the possibilities and limitations of the BDHQ for youths as a tool in sodium- and potassiumrelated healthy diet education in school settings, since other simple questionnaires have not been validated with urinary excretion of youths.

\section{Materials and Methods}

\subsection{Subjects}

The subjects were 5 th and 8 th graders (aged 10-11 years and 13-14 years, respectively) at primary and junior high schools in Shunan City, Japan, in 2011. This study was a part of the Shunan Child Cohort study 2006-2012 described in other studies [26,27]. The subjects involved in this study participated in the questionnaire survey and urine sampling between April and May 2011.

\subsection{Dietary Assessment}

The BDHQ is a 4-page, self-administered questionnaire to assess dietary intake in the previous month, which was developed to estimate nutrients using the Japanese food composition table, 5th edition. The correlation coefficients of intake estimated between singleadministered BDHQ and 16-d dietary records in adults were $0.44-0.51$ for sodium, $0.56-0.64$ for potassium, and $0.29-0.63$ for foods (cereals, noodles, bread, pulses, confectionaries, vegetables, pickled vegetables, non-alcoholic beverages, soft drinks, fish, meat, and dairy products) [22]. For the subjects who did not drink alcoholic beverages, we used a BDHQ10y version (55 food items) in the 5th grader survey and a BDHQ15y version (64 items) in the 8 th grader survey. In external validation with biomarkers, the Spearman correlation coefficients of corresponding nutrients intake using the BDHQ10y and BDHQ15y were 0.110-0.207 and $0.263-0.306$ for serum carotenoids, respectively; $0.112-0.229$ and $0.222-0.477$ for red blood corpuscle marine $\omega-3$ polyunsaturated fatty acids, respectively [24]. The correlation coefficient of protein intake with urinary nitrogen excretion in 7-9th graders was 0.1090.302 [25]. The subjects completed the BDHQ at home once during the survey period. We used the data with plausible energy intake; $\geq 0.5$ age- and sex-specific estimated energy requirements for low physical activity levels and $\leq 1.5$ energy requirements for high physical activity levels [28]. Sodium and potassium are expressed as $\mathrm{mg} /$ day $\left(\mathrm{Na} a_{B D H Q}\right.$; $\mathrm{mg}=23 \times \mathrm{mmol}$, and $K_{B D H Q} ; \mathrm{mg}=35.5 \times \mathrm{mmol}$, respectively). The intake of sodium, 
potassium, and foods (Table 1) was energy-adjusted using an energy density method (/1000 kcal). The sodium-to-potassium ratio was calculated as a molar ratio of daily intake $\left(\mathrm{Na} / \mathrm{K}_{\mathrm{BDHQ}}\right.$ ratio).

Table 1. Food groups.

\begin{tabular}{|c|c|}
\hline Food Groups & Food Items \\
\hline Meat & Poultry, meat, processed meat, liver \\
\hline Fish & Squid and octopus, shellfish, fish with bone, tuna, oily fish, dried fish, lean fish, fish paste \\
\hline Vegetables & $\begin{array}{l}\text { Raw vegetables used in salad, green leafy vegetables, broccoli, cabbage, Chinese cabbage, } \\
\text { carrots, pumpkins, radishes and turnips, other root vegetables (onions, burdock, lotus root), } \\
\text { tomato sauce, boiled tomato and stewed tomato, salted vegetable pickles }\end{array}$ \\
\hline Fruits & Citrus fruits, strawberries, persimmons, kiwi fruit, other fruits \\
\hline Cereals & $\begin{array}{l}\text { Bread: including white bread and sweet Japanese bread } \\
\text { Noodles: buckwheat noodles, Japanese wheat noodles; instant noodles, Chinese noodles, } \\
\text { spaghetti, macaroni }\end{array}$ \\
\hline Seasonings/condiments & Butter, margarine, jams, mayonnaise, ketchup, soy, and other sauces \\
\hline \multicolumn{2}{|l|}{ Fermented soybean paste (miso) } \\
\hline \multicolumn{2}{|l|}{ Noodle soup } \\
\hline Confectionaries & $\begin{array}{c}\text { Cookies, biscuits, Japanese sweets, rice crackers, rice cakes, Japanese-style pancakes, snack } \\
\text { confectionaries }\end{array}$ \\
\hline Beverages & $\begin{array}{c}\text { Green tea, black tea, oolong tea, coffee, fruits and vegetable juice, sugar-sweetened } \\
\text { beverages }\end{array}$ \\
\hline Sugar-sweetened beverages & Cola, sweetened soft drink, coffee with milk, lactobacillus beverage \\
\hline Dairy products & Milk, low-fat milk, yogurt, cheese \\
\hline
\end{tabular}

\subsection{Urinalysis}

A first-void urine specimen after waking up (overnight urine) at home was collected for annual health checkups according to the School Health and Safety Act. We used this single collection for each subject. After a mandatory dipstick test, sodium (mmol/L) and potassium $(\mathrm{mmol} / \mathrm{L})$, and creatinine $(\mathrm{mg} / \mathrm{dL})$ concentrations in the remaining urine specimen were measured using the electrode method and enzyme method, respectively, at the Tokuyama Medical Association Hospital. Daily sodium or potassium excretion was estimated based on the ratio of sodium or potassium to creatinine concentrations in overnight urine multiplied by estimated daily creatinine excretion [29]. Comparing with measurements in the 24-h urine, the intraclass correlation coefficient and the mean estimate were 0.61 and $-8.6 \%$ for sodium in 5-9th graders, respectively, and 0.55 and $-8.6 \%$ for potassium, respectively. Urinary excretion of sodium and potassium was considered as $86 \%$ and $77 \%$ of intake, respectively [30]. Finally, daily sodium, and potassium intake were expressed as $\mathrm{mg} /$ day $\left(N a_{e x}\right.$, and $K_{e x}$, respectively). $N a_{e x}$ and $K_{e x}$ divided by body weight $(\mathrm{mg} /$ day $\cdot \mathrm{kg})$ [31] were also used as an alternative intake criterion. The sodium-topotassium ratio was also calculated as a molar ratio of daily excretion $\left(\mathrm{Na} / \mathrm{K}_{e x} \mathrm{ratio}\right)$.

\subsection{Confounders}

Body height $(\mathrm{cm})$ and weight $(\mathrm{kg})$ were put in the BDHQ by the respondents. Body mass index $\left(\mathrm{BMI} ; \mathrm{kg} / \mathrm{m}^{2}\right)$ was calculated as weight/square of height $\times 10^{-4}$. Self-reported BMI before the anthropometrics at the health checkups was highly correlated with measured BMI (Pearson correlation coefficients $=0.930-0.964$ ), and the mean difference between them was -0.224 to $0.101 \mathrm{~kg} / \mathrm{m}^{2}$ in the 2006-2010 surveys [32]. A z-score BMI (zBMI) was obtained using the lambda-mu-sigma method [33], based on the 2000 Japanese reference [34]. We used the data with BMI correspondent $\geq 17 \mathrm{~kg} / \mathrm{m}^{2}$ or $\leq 30 \mathrm{~kg} / \mathrm{m}^{2}$ at 18 years for analysis to exclude possible misentry of height and weight. Ages were calculated as the 
difference between the birth date and the date when completing the questionnaire divided by 365.25 .

\subsection{Statistical Analysis}

Subjects for analysis were selected as seen in Figure 1. Variables are presented as mean \pm standard deviation. The Spearman correlation $(R h o)$ was used to examine the associations between $N a_{B D H Q}, K_{B D H Q}$, or the $N a / K_{B D H Q}$ ratio and corresponding $N a_{e x}, K_{e x}$, or the $\mathrm{Na} / \mathrm{K}_{e x}$ ratio, respectively. The subjects were stratified into five groups based on the grade- and sex-specific quintiles of each food group. The least-square means of $N a_{B D H Q}$, $K_{B D H Q}$, and the $\mathrm{Na} / \mathrm{K}_{B D H Q}$ ratio in the quintile strata were adjusted for sex, age, zBMI, and intake energy using analysis of covariance (ANCOVA), and ordinal linear trends across the quintile strata were tested to explore which food intake was associated with mineral intake. SAS version 9.4 (SAS inc. USA) was used for data analysis, where a $p$-value $<0.05$ was considered significant.

\begin{tabular}{|c|c|}
\hline $\begin{array}{l}\text { Participants, } 2684 \\
5 \text { th graders, } 1335 ; 8 \text { th graders, } 1349\end{array}$ & \\
\hline & $\begin{array}{l}\text { Students with missing value } \\
5 \text { th graders, } 105 ; 8 \text { th graders, } 103\end{array}$ \\
\hline $\begin{array}{l}\text { Students without missing responses, } 2476 \\
\text { th graders, 1230; } 8 \text { th graders, } 1246\end{array}$ & \\
\hline & $\begin{array}{l}\text { kidney disease } \\
5 \text { th graders, } 9 \text {; 8th graders, } 14\end{array}$ \\
\hline $\begin{array}{l}\text { Healthy students, } 2453 \\
5 \text { th graders, } 1221 ; 8 \text { th graders, } 1232\end{array}$ & \\
\hline s without extreme self-reported body mass index, 2444 & $\begin{array}{l}\text { Students with } \mathrm{BMI} \text { correspondent }>30 \mathrm{~kg} / \mathrm{m}^{2} \text { or }<17 \mathrm{~kg} / \mathrm{m}^{2} \\
\text { at } 18 \mathrm{y} \\
5 \text { th graders, } 4 ; 8 \text { th graders, } 5\end{array}$ \\
\hline & $\begin{array}{l}\text { Students with implausible energy intake } \\
5 \text { th graders, } 9 ; 8 \text { th graders, } 58\end{array}$ \\
\hline $\begin{array}{l}\text { Students with plausible energy intake, } 2377 \\
\text { 5th graders, } 1208 ; 8 \text { th graders, } 1169\end{array}$ & \\
\hline
\end{tabular}

Figure 1. Subject selection.

\section{Results}

Demographics, intake, and urinary excretion of minerals are presented in Table 2. The ages of the 5th and 8th graders were $10.56 \pm 0.29$ years and $13.59 \pm 0.29$ years, respectively. $\mathrm{Na}_{B D H Q}, K_{B D H Q}$, and the $\mathrm{Na} / \mathrm{K}_{B D H Q}$ ratio estimated from BDHQ were $4179 \pm 1162 \mathrm{mg} /$ day (10.6 \pm 3.0 salt-equivalent g/day), $2491 \pm 777 \mathrm{mg} /$ day, and $3.4 \pm 1.7$, respectively, and $N a_{e x}, K_{e x}$, and the $\mathrm{Na} / \mathrm{K}_{e x}$ ratio estimated from overnight urine were $3394 \pm 2072 \mathrm{mg} /$ day (8.6 \pm 5.3 salt-equivalent g/day), $1759 \pm 1275 \mathrm{mg}$ /day, and $2.7 \pm 0.6$, respectively.

The correlation coefficient between $\mathrm{Na} a_{B D H Q}$ and $N a_{e x}$ was $0.048(p=0.031$; Table 3). Using energy-adjusting $\mathrm{Na}_{B D H Q}$, or $N a_{e x}$ /weight did not improve the correlation coefficients but attenuated them, and the associations lost significance (Rho $=0.036-0.044)$. The correlation coefficients for potassium and sodium-to-potassium ratio were 0.091 and 0.096 , respectively. When energy-adjusted $K_{B D H Q}$ and weight-adjusted $K_{e x}$ were used, the coefficients improved to $0.108-0.130$. 
Table 2. Characteristics of the subjects.

\begin{tabular}{|c|c|}
\hline & $n=2377$ \\
\hline Age, years & $12.05 \pm 1.54$ \\
\hline Male: female & 1207: 1170 \\
\hline Height, cm & $147.4 \pm 11.2$ \\
\hline Weight, $\mathrm{kg}$ & $39.9 \pm 9.9$ \\
\hline Body mass index, $\mathrm{kg} / \mathrm{m}^{2}$ & $18.10 \pm 2.59$ \\
\hline zBMI & $0.02 \pm 1.03$ \\
\hline \multicolumn{2}{|l|}{ BDHQ } \\
\hline Energy & $2005 \pm 570$ \\
\hline$N a_{B D H Q}, \mathrm{mg} /$ day & $4179 \pm 1162$ \\
\hline $\mathrm{Na} a_{B D H Q}, \mathrm{mg} /$ day $1000 \mathrm{kcal}$ & $2123 \pm 402$ \\
\hline$K_{B D H Q}, \mathrm{mg} /$ day & $2491 \pm 777$ \\
\hline$K_{B D H Q}, \mathrm{mg} /$ day $\cdot 1000 \mathrm{kcal}$ & $1260 \pm 263$ \\
\hline $\mathrm{Na} / \mathrm{K}_{\mathrm{BDHQ}}$ ratio, $\mathrm{mol} / \mathrm{mol}$ & $3.4 \pm 1.7$ \\
\hline \multicolumn{2}{|l|}{ Urinary Excretion } \\
\hline$N a_{e x}, \mathrm{mg} /$ day & $3394 \pm 2071$ \\
\hline$N a_{e x} /$ weight, $\mathrm{mg} /$ day $\cdot \mathrm{kg}$ & $86.6 \pm 4702$ \\
\hline$K_{e x}, \mathrm{mg} /$ day & $1759 \pm 1275$ \\
\hline$K_{e x} /$ weight, $\mathrm{mg} /$ day $\cdot \mathrm{kg}$ & $44.9 \pm 31.2$ \\
\hline $\mathrm{Na} / \mathrm{K}_{\text {ex }}$ ratio, $\mathrm{mol} / \mathrm{mol}$ & $2.7 \pm 0.6$ \\
\hline
\end{tabular}

zBMI, z-score body mass index; $\mathrm{BDHQ}$, brief-type self-administered diet history questionnaire; $\mathrm{Na}_{B D H Q}, \mathrm{~K}_{\mathrm{BDHQ}}$ and $\mathrm{Na} / \mathrm{K}_{B D H Q}$ ratio: sodium, potassium intake, and dietary sodium-to-potassium molar ratio estimated from the BDHQ; $N a_{e x}, K_{e x}$, and $\mathrm{Na} / \mathrm{K}_{e x}$ ratio: sodium intake, potassium intake, and dietary sodium-to-potassium molar ratio estimated from overnight urine.

Table 3. Spearman's correlation coefficients (Rho) between BDHQ estimation and corresponding urinary excretion $(n=2377)$.

\begin{tabular}{|c|c|c|c|c|}
\hline & \multicolumn{4}{|c|}{ Urinary Excretion } \\
\hline & \multicolumn{2}{|c|}{ Raw Values, mg/day } & \multicolumn{2}{|c|}{$\begin{array}{l}\text { Weight Adjusted Values, } \\
\mathrm{mg} / \text { day } \cdot \mathrm{kg}\end{array}$} \\
\hline & Rho & $p$ & Rho & $p$ \\
\hline$N a_{B D H Q}, \mathrm{mg} /$ day & 0.048 & 0.031 & 0.037 & 0.074 \\
\hline$N a_{B D H Q}, \mathrm{mg} /$ day $1000 \mathrm{kcal}$ & 0.044 & 0.081 & 0.036 & 0.081 \\
\hline$K_{B D H Q}, \mathrm{mg} /$ day & 0.091 & $<0.001$ & 0.108 & $<0.001$ \\
\hline$K_{B D H Q}, \mathrm{mg} /$ day $\cdot 1000 \mathrm{kcal}$ & 0.110 & $<0.001$ & 0.130 & $<0.001$ \\
\hline $\mathrm{Na} / \mathrm{K}_{\mathrm{BDHQ}} \mathrm{ratio}, \mathrm{mol} / \mathrm{mol}$ & 0.096 & $<0.001$ & 0.130 & $<0.001$ \\
\hline
\end{tabular}

Coefficients were adjusted for sex, age, intake energy, and zBMI. BDHQ, brief-type self-administered diet history questionnaire; zBMI, z-score body mass index; $\mathrm{Na} a_{B D H Q}, K_{B D H Q}$, and $\mathrm{Na} / K_{B D H Q}$ ratio: sodium, potassium intake, and dietary sodium-to-potassium molar ratio estimated from the BDHQ.

The association between food intake classified based on quintiles of intake and urinary excretion of minerals was examined using ANCOVA (Table 4, and Supplementary Table S1). Regarding miso, the highest intake group (Q5) excreted more $N a_{e x}$ than the lowest group (Q1) did by $495 \mathrm{mg} /$ day, and the trend was significant $\left(p_{\text {trend }}<0.001\right)$. The association for pickles was also significant $\left(p_{\text {trend }}=0.005\right.$; the difference between Q1 and Q5, $319 \mathrm{mg} /$ day). Other foods were not significantly associated with $N a_{e x}$. High intake of miso and pickles was significantly and positively associated with $K_{e x}$ as with $N a_{e x}(p=0.002$ and 0.012 , respectively), whereas these foods were not associated with the $\mathrm{Na} / \mathrm{K}_{\text {ex }}$ ratio. In contrast, fruits and dairy products had favorable effects; their high intake was associated with high $K_{e x}$ and a low $\mathrm{Na} / \mathrm{K}_{e x}$ ratio $(p \leq 0.048)$. Beverages, especially sugar-sweetened beverages, were significantly associated with low $K_{e x}(p=0.004$, and 0.024 , respectively), and beverages, and seasonings/condiments had unfavorable effects on the $\mathrm{Na} / \mathrm{K}_{e x}$ ratio $(p<0.001$, and $=0.039$, respectively). The negative association between confectionaries and $K_{e x}$, and the positive association between noodles and the $\mathrm{Na} / \mathrm{K}_{e x}$ ratio were marginally significant, but other foods were not significantly associated with $K_{e x}$ or the $\mathrm{Na} / \mathrm{K}_{e x}$ ratio. 
Table 4. Least square means of minerals estimated from overnight urine (g/day) across quintile strata of food intake.

\begin{tabular}{|c|c|c|c|c|c|c|c|c|c|c|c|c|c|c|c|c|c|c|}
\hline & \multicolumn{6}{|c|}{$N a_{e x}(\mathrm{mg} / \mathrm{day})$} & \multicolumn{6}{|c|}{$K_{e x}(\mathrm{mg} /$ day $)$} & \multicolumn{6}{|c|}{$N a / K_{e x}$ Ratio } \\
\hline & Q1 & Q2 & Q3 & Q4 & Q5 & $p_{\text {trend }}$ & Q1 & Q2 & Q3 & Q4 & Q5 & $p_{\text {trend }}$ & Q1 & Q2 & Q3 & Q4 & Q5 & $p_{\text {trend }}$ \\
\hline Cereals & 3376 & 3451 & 3463 & 3371 & 3576 & 0.289 & 1763 & 1832 & 1734 & 1684 & 1784 & 0.573 & 3.3 & 3.3 & 3.4 & 3.4 & 3.5 & 0.065 \\
\hline Bread & 3447 & 3442 & 3495 & 3371 & 3481 & 0.990 & 1870 & 1686 & 1670 & 1806 & 1765 & 0.618 & 3.2 & 3.5 & 3.5 & 3.4 & 3.3 & 0.762 \\
\hline Noodles & 3358 & 3440 & 3495 & 3406 & 3538 & 0.272 & 1743 & 1727 & 1819 & 1777 & 1730 & 0.898 & 3.3 & 3.4 & 3.4 & 3.3 & 3.6 & 0.070 \\
\hline Vegetables & 3375 & 3352 & 3577 & 3531 & 3400 & 0.438 & 1777 & 1692 & 1748 & 1798 & 1782 & 0.517 & 3.4 & 3.4 & 3.5 & 3.4 & 3.3 & 0.308 \\
\hline Pickles & 3281 & 3405 & 3411 & 3579 & 3600 & 0.005 & 1694 & 1680 & 1732 & 1855 & 1831 & 0.012 & 3.3 & 3.4 & 3.4 & 3.4 & 3.5 & 0.129 \\
\hline Fruits & 3408 & 3608 & 3403 & 3490 & 3327 & 0.349 & 1695 & 1726 & 1759 & 1759 & 1858 & 0.048 & 3.5 & 3.6 & 3.3 & 3.4 & 3.1 & $<0.001$ \\
\hline Fish & 3501 & 3437 & 3444 & 3434 & 3421 & 0.581 & 1727 & 1779 & 1770 & 1812 & 1708 & 0.973 & 3.5 & 3.4 & 3.4 & 3.3 & 3.4 & 0.266 \\
\hline Salty fish & 3455 & 3599 & 3399 & 3409 & 3375 & 0.238 & 1779 & 1714 & 1804 & 1757 & 1742 & 0.861 & 3.3 & 3.6 & 3.3 & 3.4 & 3.3 & 0.184 \\
\hline Meat & 3488 & 3477 & 3360 & 3490 & 3421 & 0.685 & 1754 & 1740 & 1803 & 1772 & 1727 & 0.906 & 3.4 & 3.4 & 3.3 & 3.4 & 3.4 & 0.722 \\
\hline Processed meat & 3378 & 3536 & 3470 & 3362 & 3490 & 0.864 & 1738 & 1812 & 1715 & 1758 & 1772 & 0.939 & 3.4 & 3.4 & 3.5 & 3.3 & 3.4 & 0.875 \\
\hline Dairy product & 3436 & 3528 & 3429 & 3376 & 3467 & 0.279 & 1608 & 1768 & 1690 & 1799 & 1932 & $<0.001$ & 3.6 & 3.5 & 3.4 & 3.3 & 3.1 & $<0.001$ \\
\hline Confectionaries & 3518 & 3604 & 3315 & 3376 & 3423 & 0.162 & 1781 & 1856 & 1785 & 1687 & 1688 & 0.053 & 3.4 & 3.3 & 3.3 & 3.5 & 3.5 & 0.226 \\
\hline Japanese conf. & 3576 & 3471 & 3419 & 3461 & 3307 & 0.064 & 1774 & 1745 & 1791 & 1784 & 1701 & 0.558 & 3.4 & 3.5 & 3.4 & 3.3 & 3.3 & 0.213 \\
\hline Beverages & 3423 & 3436 & 3397 & 3498 & 3482 & 0.553 & 1910 & 1783 & 1710 & 1721 & 1673 & 0.004 & 3.1 & 3.3 & 3.4 & 3.5 & 3.6 & $<0.001$ \\
\hline SSBs & 3540 & 3427 & 3328 & 3461 & 3481 & 0.775 & 1882 & 1687 & 1826 & 1764 & 1639 & 0.024 & 3.3 & 3.5 & 3.3 & 3.3 & 3.5 & 0.218 \\
\hline Seasonings/condiments & 3419 & 3456 & 3455 & 3526 & 3379 & 0.977 & 1767 & 1801 & 1775 & 1751 & 1702 & 0.326 & 3.3 & 3.4 & 3.4 & 3.4 & 3.5 & 0.039 \\
\hline Soybean paste (miso) & 3238 & 3358 & 3436 & 3473 & 3733 & $<0.001$ & 1650 & 1693 & 1791 & 1760 & 1903 & 0.002 & 3.4 & 3.4 & 3.3 & 3.4 & 3.4 & 0.945 \\
\hline
\end{tabular}

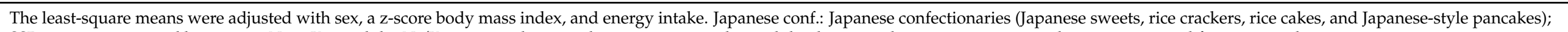

SSBs: sugar-sweetened beverages; $\mathrm{Na}_{e x}, \mathrm{~K}_{e x}$, and the $\mathrm{Na} / \mathrm{K}_{e x}$ ratio: sodium intake, potassium intake, and the dietary sodium-to-potassium molar ratio estimated from overnight urine. 


\section{Discussion}

The mean $N a_{e x}$ estimated using the overnight urine of the 5th and 8th graders was $3394 \pm 2072 \mathrm{mg} /$ day. $N a_{B D H Q}$ was $4179 \pm 1162 \mathrm{mg} /$ day, which was not only overestimated, but barely correlated with $N a_{e x}$ estimated from overnight urine $(R h o<0.1)$. The mean $K_{e x}$ was $1759 \pm 1275 \mathrm{mg} /$ day, whereas $K_{B D H Q}$ was $2491 \pm 777 \mathrm{mg} /$ day, which was overestimated, but their association was significant. The correlation of the sodium-topotassium ratio between the BDHQ and urinary excretion was also significant. Miso and pickles estimated from the BDHQ were significantly associated with $N a_{e x}$ and $K_{e x}$, but not with the $\mathrm{Na} / \mathrm{K}_{e x}$ ratio. The intake of fruits and dairy products was favorable because it was associated with the high $K_{e x}$ and low $N a / K_{e x}$ ratio, and the intake of beverages, sugar sweetened beverages, and seasonings was unfavorable.

\subsection{Foods Associated with Sodium, Potassium, and Sodium-to-Potassium Ratio}

Several foods were positively or negatively related to $N a_{e x}, K_{e x}$, or the $N a / K_{e x}$ ratio, but there were neither foods with common beneficial effects on $N a_{e x}, K_{e x}$, the $N a / K_{e x}$ ratio, nor foods with common adverse effects. For example, the intake of miso and pickles was significantly associated with high $N a_{e x}$, and positively associated with high $K_{e x}$. These foods are blamed for high sodium intake in the Japanese diet, but rather miso had a beneficial effect on blood pressure $[35,36]$. In studies concurrently assessing sodium, potassium, and a sodium-to-potassium ratio of youths, sodium assessed from urinary excretion or dietary records was not associated with blood pressure, but potassium was negatively associated, and the sodium-to-potassium ratio was positively associated with it [11,12]. Similar findings were seen in studies on adults using a 24-h urine collection and dietary assessment [37]. When focusing on controlling the population's blood pressure, dietary habits and patterns with foods lowering the sodium-to-potassium ratio, high proportions of fruits and dairy products, and low proportions of beverages and seasonings/condiments should be recommended.

It is difficult to explain why beverages were related to low potassium intake and a high dietary sodium-to-potassium ratio. In a study in the United Kingdom, people with a high consumption of ultra-processed foods had a higher intake of sodium and lower intake of potassium [38]. Japanese adolescents who frequently consumed take-out dishes and food from convenience stores had higher urinary sodium excretion than adolescents who consumed these foods less frequently [39]. Consumption of beverages may be related to increased consumption of processed foods and out-of-home behaviors.

\subsection{Sodium Intake}

In this study, miso and pickles were found to have a significant association with $N a_{e x}$. This assessment is available for food education to reduce sodium intake, but the assessment of major sources, such as seasonings/condiments, cereals, and fish, is not very useful to elucidate high sodium intake. In a previous study of Japanese adults, where a dietary assessment was designed to measure discretionary salt intake with scaling discretionary amounts of soy sauce, the major contributors to total sodium intake were significantly associated with urinary sodium excretion [31]. The BDHQ was designed to capture Japanese dietary habits, but is not specific for sodium intake.

\subsection{Potassium Intake}

$K_{B D H Q}$ was overestimated more than $N a_{B D H Q}$ was with excretion as references. Sodium and potassium are excreted in sweat and feces in addition to urine. When calculating $N a_{e x}$ and $K_{e x}$, we considered this extra-urinary excretion larger for potassium than for sodium. Extra-urinary excretion could be underestimated. Loss of potassium during cooking [40-42] is another explanation for the overestimation of $K_{B D H Q}$. Unlike sodium from seasonings/condiments, potassium is rich in various core foods, such as vegetables, fish, and meats [43]; skin-stripping and boiling can lead to the loss of potassium during cooking. 
In contrast, the association between intake and excretion was stronger for potassium than for sodium. It is difficult for youths to know discretionary use of sodium during cooking and at the table, unlike the intake of core foods contributing to potassium intake. The dietary habits of youths with regard to high intake of potassium, rather than sodium, can be determined from the BDHQ assessment. However, we did not find a positive association of vegetables and fish as seen in a study of Japanese adults [44]. Other than the explanations mentioned above, various foods included in food groups and knowledge about favorable effects of vegetables and fish may attenuate or obscure the association between the intake of core foods and $K_{e x}$.

\subsection{Simple Questionnaires}

Typical food frequency questionnaires have 80 to 120 food items. The BDHQ, which was simplified from the DHQ with 151 food items to reduce a respondent burden [22,45], is available to enhance self-awareness and assess population levels of dietary intake in school settings. In addition to the BDHQ, simple Japanese questionnaires have been used [46-48]. The Salt Check Sheet has 13 items and a score range of 0-35. Correlation coefficients of the scores for adults were 0.30 with estimates from spot urine [47], and 0.27 with measurements from 24 -h urine [21]. Its validity has not been examined using urinary sodium excretion in youths, but a correlation coefficient between the scores and $N a_{B D H Q}$ was 0.408 for 5 th and 7th graders [49], which was higher than those with urinary estimates for adults $(0.27-0.30)$. The high correlation between the Salt Check Sheet and the BDHQ may be explained by similar items used for estimation. There were other brief questionnaires for estimation of salt intake, originating from a tool of the Japanese Ministry of Health and Welfare $[46,50,51]$. One was used for adolescents and revealed the association between salt intake and blood pressure [51]. However, validation was examined comparing with weighted dietary records, which showed a correlation coefficient of 0.28 in adults. If the coefficients with urinary sodium would be used, the correlations may be lower. Food frequency questionnaires reduced the burden of target subjects, added to which the BDHQ can assess dietary potassium and a sodium-to-potassium ratio other than dietary sodium.

\subsection{Meeting the References}

A proposed tentative dietary goal for preventing lifestyle diseases (DG) was to reduce salt intake in Japan: $<6.0 \mathrm{~g} /$ day for both sexes aged 10-11 years, and $<6.5$ and $<7.0 \mathrm{~g} /$ day for girls and boys aged 12-14 years, respectively [28]. The DG for potassium is $\geq 2000$ and $\geq 2200 \mathrm{mg}$ /day for girls and boys aged 10-11 years, respectively, and $2400 \mathrm{mg} /$ day for both sexes aged 12-14 years. The mean salt-equivalent $N a_{e x}$ of the subjects in this study was higher, and $K_{e x}$ was lower than the DGs for corresponding ages, but several considerations were needed before comparing them. First, a gold standard for estimating daily sodium and potassium intake is measuring 24-h urinary excretion. The equation to estimate $N a_{e x}$ and $K_{e x}$ from overnight urine was developed using 24-h urinary excretion with an intraclass correlation (validity coefficient) of 0.55-0.61 [29]. Second, daily sodium and potassium intake vary each day. This intra-individual variation is quantifiable by repeated measurement, but only single overnight urine specimens were available in this study. These measurement errors inflate the standard deviation of $N a_{e x}$ and $K_{e x}$ and attenuate correlation coefficients with other variables, such as the estimates from the BDHQ [52,53]. At least more than half of the youths may overconsume sodium, and another more than half may have insufficient potassium intake because the mean salt-equivalnet $N a_{e x}$ was higher, and the mean $K_{e x}$ was lower than the DGs. Moreover, the sodium-to-potassium ratio in this population highly exceeded the recommendation of the World Health Organization (1.0) [8].

\subsection{Strengths and Limitations}

A high retention rate and a large sample size were the strengths of this study. On the other hand, several limitations should be considered to interpret the results. First, it is 
possible that the foods associated with sodium, potassium, and the sodium-to-potassium ratio in this study indirectly link to the intake of these minerals. Collateral food intake could influence the associations, but youths can evaluate their dietary intake from the BDHQ, which would help them modify their dietary habits. In other words, a dietary pattern or quality assessment have the potential to elucidate the association with the health outcomes. Second, correlations in this study were attenuated because of the single overnight urine specimen, as mentioned above. Repeated urinary excretion measurement would be better. Third, the calculation of $N a_{e x}$ and $K_{e x}$ was based on self-reported anthropometrics. We excluded the subjects with obesity, whose daily creatinine excretion would be overestimated [29]. Fourth, the survey was restricted to a local city, and the results have limited generalizability to other populations. Possible regional variability of dietary habits in Japan should be elucidated in the future.

\section{Conclusions}

$\mathrm{Na} a_{B D H Q}$ estimated using the BDHQ for youths was associated with urinary sodium excretion, but the correlation coefficient was lower than 0.1. Instead, $K_{B D H Q}$ and the $N a / K_{B D H Q}$ ratio had higher correlations with urinary excretion than $\mathrm{Na}_{B D H Q}$ did in Japanese youths. Miso and pickles intake measured using the BDHQ for youths was associated with $\mathrm{Na}_{e x}$; the assessment of foods instead of sodium intake is better to estimate sodium consumption as alternatives and allow youths to evaluate their own dietary habits. Considering the importance of prevention of hypertension from childhood, dietary habits with high proportions of fruits and dairy products, and avoidance of high intakes of beverages, seasonings/condiments are encouraged to reduce the dietary sodium-to-potassium ratio. After deciding the target nutrients, the BDHQ is available as a school health education tool. When using the BDHQ to assess youth sodium and potassium intake, overestimation, a sample size, and possible confounders should be taken account of.

Supplementary Materials: The following are available online at https:/ / www.mdpi.com/article/10 .3390/nu13072345/s1, Table S1: Distribution of food intake as median of quintile strata (g/1000 kcal).

Author Contributions: Conceptualization, M.O.; and S.S.; methodology, M.O.; and S.S.; formal analysis, M.O.; investigation, M.O.; resources, S.S.; data curation, M.O.; writing-original draft preparation, M.O.; writing-review and editing, S.S.; visualization, M.O.; project administration, M.O.; funding acquisition, M.O. All authors have read and agreed to the published version of the manuscript.

Funding: This manuscript preparation was funded by the Japan Society for the Promotion of Science, grant numbers JP18K10085, and JP21K10497.

Institutional Review Board Statement: The study was conducted according to the guidelines of the Declaration of Helsinki and approved by the Institutional Review Board, Yamaguchi University Hospital (H17-14-2, 22 March 2006), and the education board of Shunan City.

Informed Consent Statement: Informed consent was obtained from all subjects involved in the study. All subjects involved in the study gave assent, and their guardians provided written informed consent.

Data Availability Statement: The data presented in this study are available on request from the corresponding author.

Acknowledgments: We appreciated the understanding about this study and the collaboration of the health center, the education board and schools of Shunan City. We appreciate the participants and their guardians. We would like to thank Ichiro Kunitsugu, Shin-ichi Sugiyama, and Norikazu Yoshitake for their help with the survey. We would like to thank Keiko Asakura for her critical suggestions about preparing the manuscript.

Conflicts of Interest: The authors declare no conflict of interest. The funders had no role in the design of the study, in the collection, analyses, or interpretation of data, in the writing of the manuscript, or in the decision to publish the results. 


\section{References}

1. GBD 2017 Diet Collaborators. Health effects of dietary risks in 195 countries, 1990-2017: A systematic analysis for the Global Burden of Disease Study 2017. Lancet 2019, 393, 1958-1972. [CrossRef]

2. Aparicio, A.; Rodríguez-Rodríguez, E.; Cuadrado-Soto, E.; Navia, B.; López-Sobaler, A.M.; Ortega, R.M. Estimation of salt intake assessed by urinary excretion of sodium over $24 \mathrm{~h}$ in Spanish subjects aged 7-11 years. Eur. J. Nutr. 2015, 56, 171-178. [CrossRef] [PubMed]

3. He, F.J.; Marrero, N.M.; MacGregor, G.A. Salt and blood pressure in children and adolescents. J. Hum. Hypertens. 2007, $22,4-11$. [CrossRef] [PubMed]

4. Leyvraz, M.; Chatelan, A.; Da Costa, B.R.; Taffé, P.; Paradis, G.; Bovet, P.; Bochud, M.; Chiolero, A. Sodium intake and blood pressure in children and adolescents: A systematic review and meta-analysis of experimental and observational studies. Int. J. Epidemiol. 2018, 47, 1796-1810. [CrossRef] [PubMed]

5. Rios-Leyvraz, M.; Bloetzer, C.; Chatelan, A.; Bochud, M.; Burnier, M.; Santschi, V.; Paradis, G.; Tabin, R.; Bovet, P.; Chiolero, A. Sodium intake and blood pressure in children with clinical conditions: A systematic review with meta-analysis. J. Clin. Hypertens. 2018, 21, 118-126. [CrossRef] [PubMed]

6. Chen, X.; Wang, Y. Tracking of Blood Pressure from Childhood to Adulthood. Circulation 2008, 117, 3171-3180. [CrossRef]

7. Toschke, A.M.; Kohl, L.; Mansmann, U.; Von Kries, R. Meta-analysis of blood pressure tracking from childhood to adulthood and implications for the design of intervention trials. Acta Paediatr. 2009, 99, 24-29. [CrossRef]

8. WHO. Guideline: Sodium Intake for Adults and Children; WHO: Geneva, Switzerland, 2012; ISBN 978-92-4-150483-6.

9. Binia, A.; Jaeger, J.; Hu, Y.; Singh, A.; Zimmermann, D. Daily potassium intake and sodium-to-potassium ratio in the reduction of blood pressure: A meta-analysis of randomized controlled trials. J. Hypertens. 2015, 33, 1509-1520. [CrossRef]

10. Perez, V.; Chang, E.T. Sodium-to-Potassium Ratio and Blood Pressure, Hypertension, and Related Factors. Adv. Nutr. 2014, 5, 712-741. [CrossRef]

11. Geleijnse, J.M.; Grobbee, D.; Hofman, A. Sodium and potassium intake and blood pressure change in childhood. BMJ 1990, 300, 899-902. [CrossRef]

12. Buendia, J.R.; Bradlee, M.L.; Daniels, S.R.; Singer, M.R.; Moore, L.L. Longitudinal Effects of Dietary Sodium and Potassium on Blood Pressure in Adolescent Girls. JAMA Pediatr. 2015, 169, 560-568. [CrossRef]

13. Martinez-Aguayo, A.G.; Campino, C.; Rodriguez-Fernandez, M.; Poggi, H.; D’Apremont, I.; Moore, R.; Garcia, H.; Solari, S.; Allende, F.; Peredo, S.; et al. Urinary sodium-to-potassium ratio and plasma renin and aldosterone concentrations in normotensive children: Implications for the interpretation of results. J. Hypertens. 2020, 38, 671-678. [CrossRef] [PubMed]

14. Trieu, K.; Neal, B.; Hawkes, C.; Dunford, E.; Campbell, N.R.C.; Rodriguez-Fernandez, R.; Legetic, B.; McLaren, L.; Barberio, A.; Webster, J. Salt Reduction Initiatives around the World-A Systematic Review of Progress towards the Global Target. PLoS ONE 2015, 10, e0130247. [CrossRef] [PubMed]

15. Anderson, C.A.; Appel, L.J.; Okuda, N.; Brown, I.J.; Chan, Q.; Zhao, L.; Ueshima, H.; Kesteloot, H.; Miura, K.; Curb, J.D.; et al. Dietary Sources of Sodium in China, Japan, the United Kingdom, and the United States, Women and Men Aged 40 to 59 Years: The INTERMAP Study. J. Am. Diet. Assoc. 2010, 110, 736-745. [CrossRef] [PubMed]

16. Hyseni, L.; Elliot-Green, A.; Lloyd-Williams, F.; Kypridemos, C.; O’Flaherty, M.; McGill, R.; Orton, L.; Bromley, H.; Cappuccio, F.P.; Capewell, S. Systematic review of dietary salt reduction policies: Evidence for an effectiveness hierarchy? PLoS ONE 2017, 12, e0177535. [CrossRef]

17. Asakura, K.; Uechi, K.; Masayasu, S.; Sasaki, S. Sodium sources in the Japanese diet: Difference between generations and sexes. Public Health Nutr. 2016, 19, 2011-2023. [CrossRef] [PubMed]

18. Grimes, C.A.; Campbell, K.J.; Riddell, L.J.; Nowson, C.A. Sources of sodium in Australian children's diets and the effect of the application of sodium targets to food products to reduce sodium intake. Br. J. Nutr. 2010, 105, 468-477. [CrossRef]

19. Blanco-Metzler, A.; Núñez-Rivas, H.; Vega-Solano, J.; Montero-Campos, M.; Benavides-Aguilar, K.; Cubillo-Rodríguez, N. Household Cooking and Eating out: Food Practices and Perceptions of Salt/Sodium Consumption in Costa Rica. Int. J. Environ. Res. Public Health 2021, 18, 1208. [CrossRef]

20. Uechi, K.; Kobayashi, S.; Sugimoto, M.; Sasaki, S. Urine 24-Hour Sodium Excretion Decreased between 1953 and 2014 in Japan, but Estimated Intake Still Exceeds the WHO Recommendation. J. Nutr. 2017, 147, 390-397. [CrossRef]

21. Yasutake, K.; Miyoshi, E.; Kajiyama, T.; Umeki, Y.; Misumi, Y.; Horita, N.; Murata, Y.; Ohe, K.; Enjoji, M.; Tsuchihashi, T. Comparison of a salt check sheet with 24-h urinary salt excretion measurement in local residents. Hypertens. Res. 2016, 39, 879-885. [CrossRef]

22. Kobayashi, S.; Honda, S.; Murakami, K.; Sasaki, S.; Okubo, H.; Hirota, N.; Notsu, A.; Fukui, M.; Date, C. Both Comprehensive and Brief Self-Administered Diet History Questionnaires Satisfactorily Rank Nutrient Intakes in Japanese Adults. J. Epidemiol. 2012, 22, 151-159. [CrossRef] [PubMed]

23. Sakata, S.; Tsuchihashi, T.; Oniki, H.; Tominaga, M.; Arakawa, K.; Sakaki, M.; Kitazono, T. Relationship between salt intake as estimated by a brief self-administered diet-history questionnaire (BDHQ) and 24-h urinary salt excretion in hypertensive patients. Hypertens. Res. 2015, 38, 560-563. [CrossRef] [PubMed]

24. Okuda, M.; Sasaki, S.; Bando, N.; Hashimoto, M.; Kunitsugu, I.; Sugiyama, S.; Terao, J.; Hobara, T. Carotenoid, Tocopherol, and Fatty Acid Biomarkers and Dietary Intake Estimated by Using a Brief Self-Administered Diet History Questionnaire for Older Japanese Children and Adolescents. J. Nutr. Sci. Vitaminol. 2009, 55, 231-241. [CrossRef] [PubMed] 
25. Okuda, M.; Asakura, K.; Sasaki, S. Protein Intake Estimated from Brief-Type Self-Administered Diet History Questionnaire and Urinary Urea Nitrogen Level in Adolescents. Nutrients 2019, 11, 319. [CrossRef] [PubMed]

26. Okuda, M.; Sugiyama, S.; Kunitsugu, I.; Hinoda, Y.; Okuda, Y.; Shirabe, K.; Yoshitake, N.; Hobara, T. Use of Body Mass Index and Percentage Overweight Cutoffs to Screen Japanese Children and Adolescents for Obesity-Related Risk Factors. J. Epidemiol. 2010, 20, 46-53. [CrossRef] [PubMed]

27. Shinozaki, K.; Okuda, M.; Kunitsugu, I.; Shigeta, M.; Sasaki, S. Dietary Fiber Consumption Decreases the Risks of Overweight and Hypercholesterolemia in Japanese Children. Ann. Nutr. Metab. 2015, 67, 58-64. [CrossRef]

28. Ito, S.; Sasaki, S. Dietary Reference Intakes for Japanese; Daiichi-Shuppan: Tokyo, Japan, 2020; ISBN 978-4-8041-1408-8.

29. Okuda, M.; Asakura, K.; Sasaki, S. Estimation of daily sodium and potassium excretion from overnight urine of Japanese children and adolescents. Environ. Health Prev. Med. 2020, 25, 1-6. [CrossRef] [PubMed]

30. Holbrook, J.T.; Patterson, K.Y.; Bodner, J.; Douglas, L.W.; Veillon, C.; Kelsay, J.L.; Mertz, W.; Smith, J.C. Sodium and potassium intake and balance in adults consuming self-selected diets. Am. J. Clin. Nutr. 1984, 40, 786-793. [CrossRef] [PubMed]

31. Okuda, N.; Okayama, A.; Miura, K.; Yoshita, K.; Saito, S.; Nakagawa, H.; Sakata, K.; Miyagawa, N.; Chan, Q.; Elliott, P.; et al. Food sources of dietary sodium in the Japanese adult population: The international study of macro-/micronutrients and blood pressure (INTERMAP). Eur. J. Nutr. 2016, 56, 1269-1280. [CrossRef]

32. Yoshitake, N.; Okuda, M.; Sasaki, S.; Kunitsugu, I.; Hobara, T. Validity of self-reported body mass index of Japanese children and adolescents. Pediatr. Int. 2012, 54, 397-401. [CrossRef]

33. Cole, T.J.; Green, P.J. Smoothing reference centile curves: The lms method and penalized likelihood. Stat. Med. 1992, 11, 1305-1319. [CrossRef]

34. Kato, N.; Takimoto, H.; Sudo, N. The Cubic Functions for Spline Smoothed L, S and M Values for BMI Reference Data of Japanese Children. Clin. Pediatr. Endocrinol. 2011, 20, 47-49. [CrossRef] [PubMed]

35. Ito, K.; Miyata, K.; Mohri, M.; Origuchi, H.; Yamamoto, H. The Effects of the Habitual Consumption of Miso Soup on the Blood Pressure and Heart Rate of Japanese Adults: A Cross-sectional Study of a Health Examination. Intern. Med. 2017, 56, 23-29. [CrossRef] [PubMed]

36. Wakasugi, M.; Kazama, J.J.; Narita, I. Associations between the Intake of Miso Soup and Japanese Pickles and the Estimated 24-h Urinary Sodium Excretion: A Population-based Cross-sectional Study. Intern. Med. 2015, 54, 903-910. [CrossRef]

37. Iwahori, T.; Miura, K.; Ueshima, H. Time to Consider Use of the Sodium-to-Potassium Ratio for Practical Sodium Reduction and Potassium Increase. Nutrients 2017, 9, 700. [CrossRef]

38. Rauber, F.; Louzada, M.L.D.C.; Steele, E.M.; Millett, C.; Monteiro, C.A.; Levy, R.B. Ultra-Processed Food Consumption and Chronic Non-Communicable Diseases-Related Dietary Nutrient Profile in the UK (2008-2014). Nutrients 2018, 10, 587. [CrossRef] [PubMed]

39. Okuda, M.; Asakura, K.; Sasaki, S. Placing Salt/Soy Sauce at Dining Tables and Out-of-Home Behavior Are Related to Urinary Sodium Excretion in Japanese Secondary School Students. Nutrients 2017, 9, 1290. [CrossRef]

40. Stewart, C.P. Loss of Nutrients in Cooking. Proc. Nutr. Soc. 1946, 4, 164-171. [CrossRef]

41. Eaton, S.; Konner, M. Review Paleolithic nutrition revisited: A twelve-year retrospective on its nature and implications. Eur. J. Clin. Nutr. 1997, 51, 207-216. [CrossRef]

42. Kimura, M.; Itokawa, Y. Cooking losses of minerals in foods and its nutritional significance. J. Nutr. Sci. Vitaminol. 1990,36 (Suppl. S1), S25. [CrossRef]

43. Grimes, C.A.; Riddell, L.J.; Campbell, K.J.; Beckford, K.; Baxter, J.R.; He, F.J.; Nowson, C. Dietary intake and sources of sodium and potassium among Australian schoolchildren: Results from the cross-sectional Salt and Other Nutrients in Children (SONIC) study. BMJ Open 2017, 7, e016639. [CrossRef]

44. Okuda, N.; Okayama, A.; Miura, K.; Yoshita, K.; Miyagawa, N.; Saitoh, S.; Nakagawa, H.; Sakata, K.; Chan, Q.; Elliott, P.; et al. Food Sources of Dietary Potassium in the Adult Japanese Population: The International Study of Macro-/Micronutrients and Blood Pressure (INTERMAP). Nutrients 2020, 12, 787. [CrossRef]

45. Sasaki, S.; Yanagibori, R.; Amano, K. Self-Administered Diet History Questionnaire Developed for Health Education: A Relative Validation of the Test-Version by Comparison with 3-Day Diet Record in Women. J. Epidemiol. 1998, 8, 203-215. [CrossRef] [PubMed]

46. Itoh, K.; Masuda, A.; Uezono, K.; Kawasaki, T. Assessment of Dietary Intake Estimation Using a Simple Questionnaire Method. Nippon. Eiyo Shokuryo Gakkaishi 1992, 45, 535-543. [CrossRef]

47. Tsuchihashi, T.; Masuda, K.; Oniki, H.; Sakaki, M.; Arakawa, H.; Kameda, W.; Fukui, H. Validity of salt check sheet in hepertesive patients: Assessment of salt intake by using a simple check sheet in hypertensive patients. J. Blood Press. 2013, 20, $1239-1243$.

48. Seko, C.; Odani, K.; Wada, S.; Yoshii, K.; Segawa, H.; Kitaoka, K.; Masumoto, T.; Higashi, A. Characteristic dietary habits associated with high values of estimated 24-hours urinary sodium excretion and sodium-to-potassium ratio assessed by age group among the residents of a rural town in Japan. Clin. Exp. Hypertens. 2019, 42, 449-459. [CrossRef]

49. Fujiwara, T.; Kikuchi, K.; Hoshide, S.; Tsuchihashi, T.; Kario, K. Usefulness of a salt check sheet for elementary school and junior high school children. J. Clin. Hypertens. 2019, 21, 722-729. [CrossRef]

50. Morimoto, A.; Takase, S.; Hada, K.; Hosoya, N. Evaluation of a Covinient Method for the estimation of dietary food consumption. Jap. J. Nutr. 1977, 35, 235-245. [CrossRef] 
51. Sougawa, Y.; Miyai, N.; Morioka, I.; Utsumi, M.; Takeda, S.; Miyashita, K.; Arita, M. The combination of obesity and high salt intake are associated with blood pressure elevation among healthy Japanese adolescents. J. Hum. Hypertens. 2020, 34, 117-124. [CrossRef]

52. Armstrong, B.K.; White, E.; Saracci, R. Principles of Exposure Measurement in Epidemiology: Monographs in Epidemiology and Biostatistics; Oxford University Press: New York, NY, USA, 1992; ISBN 978-0192617057.

53. Willet, W. Nutritional Epidemiology; Oxford University Press: New York, NY, USA, 2013; ISBN 978-0-19-975403-8. 